\title{
The effectiveness of ultrasonography in verifying the placement of a nasogastric tube in patients with low consciousness at an emergency center
}

\author{
Hyung Min Kim ${ }^{1}$, Byung Hak So ${ }^{1}$, Won Jung Jeong ${ }^{1}$, Se Min Choi ${ }^{2}$ and Kyu Nam Park ${ }^{3 *}$
}

\begin{abstract}
Background: This study was designed to compare the effectiveness of using auscultation, $\mathrm{pH}$ measurements of gastric aspirates, and ultrasonography as physical examination methods to verify nasogastric tube(NGT) placement in emergency room patients with low consciousness who require NGT insertion.

Methods: The study included 47 patients who were all over 18 years of age. In all patients, tube placement was verified by chest $\mathrm{X}$-rays. Auscultation, $\mathrm{pH}$ analysis of gastric aspirates, and ultrasonography were conducted on each patient in random order. The mean patient age was $57.62 \pm 17.24$ years, and 28 males (59.6\%) and 19 females (40.4\%) were included. The NGT was inserted by an emergency room resident. For $\mathrm{pH}$ testing, gastric aspirates were dropped onto litmus paper, and the resulting color of the paper was compared with a reference table. Ultrasonography was performed by an emergency medicine specialist, and the chest X-ray examination was interpreted by a different emergency medicine specialist who did not conduct the ultrasonography test. The results of the auscultation, gastric aspirate $\mathrm{pH}$, and ultrasonography examinations were compared with the results of the chest $x$-ray examination.
\end{abstract}

Results: The sensitivity and specificity were $100 \%$ and $33.3 \%$, respectively, for auscultation and $86.4 \%$ and $66.7 \%$, respectively, for ultrasonography. Kappa values were the highest for auscultation at 0.484 compared to chest $x$-rays, followed by 0.299 for ultrasonography and 0.444 for $\mathrm{pH}$ analysis of the gastric aspirate. The ultrasonography has a positive predictive value of $97.4 \%$ and a negative predictive value of $25 \%$.

Conclusions: Ultrasonography is useful for confirming the results of auscultation after NGT insertion among patients with low consciousness at an emergency center. When ultrasound findings suggest that the NGT placement is not gastric, additional chest X-ray should be performed.

Keywords: Nasogastric tube, pH, Ultrasonography, Auscultation

\section{Introduction}

NGT insertion is one of the most commonly performed procedure in an emergency setting. It is usually performed in patients who are being treated for intestinal adhesions, suspicion of gastric bleeding, overdose, or who require mechanical ventilation after endotracheal intubation. Whilst the misplacement rate appears low, the complications may be very serious. A major complication of this procedure is the aspiration of gastric

\footnotetext{
*Correspondence: emsky@catholic.ac.kr

${ }^{3}$ Department of Emergency Medicine, College of Medicine, The Catholic University of Korea, St. Mary's Hospital, Seoul, South Korea

Full list of author information is available at the end of the article
}

contents which could lead even to death, especially high in patients with low consciousness and increases if food or medicine is administered through a NGT whose port is incorrectly placed in the mouth, the esophagus, or the esophagogastric junction [1-4]. Aspiration can be caused by regurgitation during the insertion of the tube, esophageal perforation, or accidental placement of the tube in the respiratory tract or the cranial cavity. Even when the tube is correctly placed within the stomach, it can be dislocated when the patient coughs, sneezes, or vomits.

Several methods have been suggested for verifying the placement of a NGT, including auscultation, measuring the $\mathrm{pH}$ of aspirates from the tube, and chest $\mathrm{x}$-rays. In addition, the use of colorimetric capnography has been 
demonstrated recently $[5,6]$. Auscultation with a stethoscope confirms gurgling sounds in the epigastrium when air is injected after NGT insertion. However, in the noisy environment of an emergency room, sounds associated with the incorrect placement of the NGT in the lungs or in the esophagus might be mistaken for those associated with the correct placement of the tube, and a basic chest $\mathrm{X}$-ray is recommended in most cases [7-9]. But chest Xrays have issues of their own, including delayed verification, radiation exposure, and cost. In most emergency rooms, chest X-rays are not performed immediately after NGT insertion. Because the verification of tube placement instead usually relies on auscultation, a significant risk of complications remains, especially in patients with low consciousness. Aspirating the nasogastric tube contents and using litmus paper to measure the $\mathrm{pH}$ of the aspirates is an alternative method for verifying tube placement. This method has been reported to be effective for verifying the placement of the nasogastric feeding tube and for the continuous monitoring of intensive care unit patients [10-12]. However, to date, no other recommendations or alternative methods have been proposed for emergency room settings. In addition, ultrasonography is currently used in many settings, including the emergency room. The frequent use of this procedure according to the needs of the patient is helpful for making the correct medical judgments. Therefore, this study was designed to compare the effectiveness and the limitations of conventional auscultation, $\mathrm{pH}$ analysis of the tube aspirate, chest X-ray, and ultrasonography for verifying the placement of a NGT in patients with low consciousness at an emergency center.

\section{Methods}

\section{Settings and patients}

This prospective study was conducted over 5 months (from May to September 2011) at a local emergency center visited by 55,000 patients annually. Participants in the trial included patients with low consciousness in whom correct placement of the NGT was ultimately verified by chest X-ray. All patients were over 18 years of age and underwent NGT insertions for reasons including drug overdose, suspicion of gastric bleeding, endotracheal intubation, and others.

\section{Outcome measures}

NGT insertion was performed bedside by a emergency room resident physician by measuring the distance from the tip of the patient's nose to the earlobe and from the earlobe to the xiphisternum. NGTs were inserted to a length $10 \mathrm{~cm}$ longer than the distance obtained by this measurement. The tube size was 16 Fr. After the insertion, auscultation, $\mathrm{pH}$ testing of the tube aspirate, and ultrasonography (GE LOGIQ 400, USA) were conducted in random order, and the results were recorded.

Auscultation was performed by assessing sounds in the epigastrium while injecting 10-20 cc of air into the NGT with a 50 cc syringe. The results of this examination were also recorded. The gastric $\mathrm{pH}$ analysis was performed by dropping a sample that was aspirated from the tube onto a litmus strip (TOYO ROHIO CO. LTD). The $\mathrm{pH}$ reading was recorded based on color-coded reference values, and the tube placement was considered to be gastric if the $\mathrm{pH}$ was less than 5 [10]. Ultrasound examinations were conducted by 2 emergency medicine specialists who received basic training on the routine use of ultrasound to verify NGT insertion. Final confirmation of the gastric placement of the tube was obtained by chest X-ray that is the test method reference standard to confirm correct NGT placement. Chest X-rays were interpreted by an emergency medicine specialist who did not perform the ultrasound examinations.

Ultrasound examinations included a transversal scan that was performed prior to tube insertion from either the right or left side of the patient's neck. This scan was performed to verify that the esophagus was located behind the respiratory tract. If attenuated ultrasound waves in the far field and the posterior wall of the esophagus were not observed after tube insertion, the NGT was considered to be positioned within the cervical esophagus (Figure 1). In the esophagogastric junction, the NGT was directly visualized with longitudinal and angled scans of the epigastrium. Visualization of the NGT in separate scans of the fundus and the antrum of stomach was attempted. We used linear probe for the study of the neck and convex probe for stomach. If visualization was not possible, $40 \mathrm{cc}$ of normal saline and $10 \mathrm{cc}$ of air were injected through the NGT and if ultrasonography showed dynamic fogging in the stomach, gastric placement of the tube was verified (Figures 2 and 3). This study was approved by the Bioethics Committee at the Catholic University of Korea.

\section{Statistical methods}

In the descriptive statistical analysis, continuous variables were reported in terms of the mean and standard deviation, and nominal variables were reported in terms of frequency and percentage. Sensitivity, specificity, positive predictive value, and negative predictive value were calculated to assess the diagnostic ability of the techniques studied in this research, and Cohen's kappa analysis was conducted to evaluate the degree of concordance. SPSS for Windows (ver. 18.0, SPSS Inc., Chicago, USA) was used for statistical analysis. $P$ values less than 0.05 were considered to indicate statistical significance. 

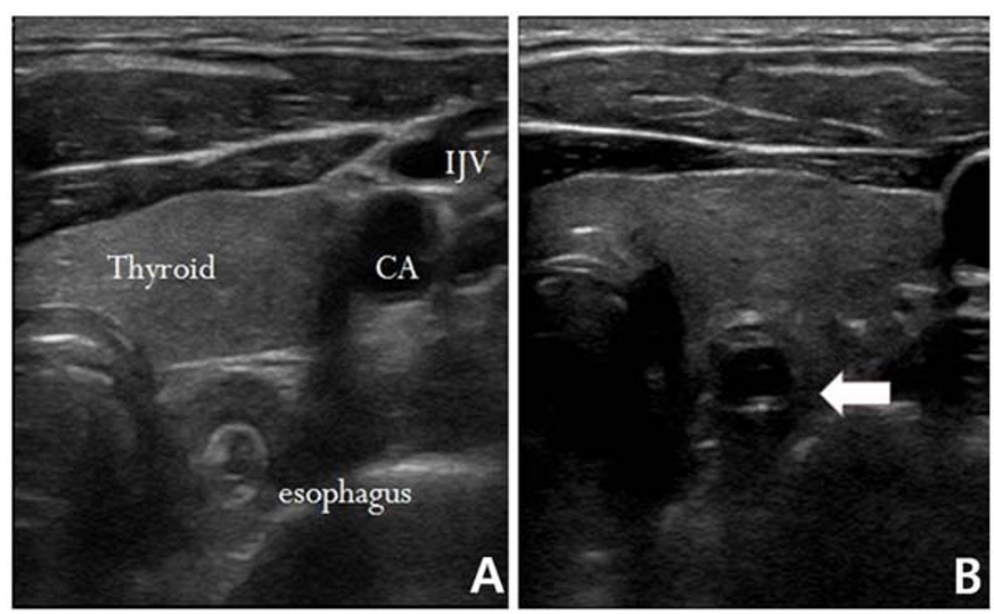

Figure 1 Normal esophagus (A). White arrow indicates the nasogastric tube in the esophagus (B).

\section{Results}

A total of 74 patients were screened for the study. Seventeen patients with normal levels of consciousness were excluded. Ten more patients were excluded because they did not undergo a radiological examination after tube insertion. Thus, a total of 47 patients composed the study sample. The mean age of the patients was $57.62 \pm$ 17.24 years. Among the patients with a Glasgow Coma Scale (GCS) score lower than 14, 27 patients (57.4\%) underwent endotracheal intubation because of pneumonia, overdose, external injury, or CPR. This group accounted for the largest share of the patients, followed by poisoning, gastrointestinal bleeding, and intestinal adhesions (Table 1).
Of the 47 patients who underwent chest X-rays, the NGT was verified to be in the stomach for 44 patients (93.6\%). In the remaining 3 patients, the tube had been placed in the esophagus. None of the tubes had been placed in the bronchial tubes or in the cranial cavity. Among the methods for tube placement verification tested in this study, auscultation had the highest sensitivity at $100 \%$; however, its specificity was low at 33.3. Auscultation suggested that the tube was in the stomach when it was in fact in the esophagus in 2 patients ( 1 patient with intestinal adhesion and 1 who had undergone endotracheal intubation).

Of the 3 patients with incorrectly diagnosed gastric placement of the NGT based on $\mathrm{pH}$ analysis, the $\mathrm{pH}$

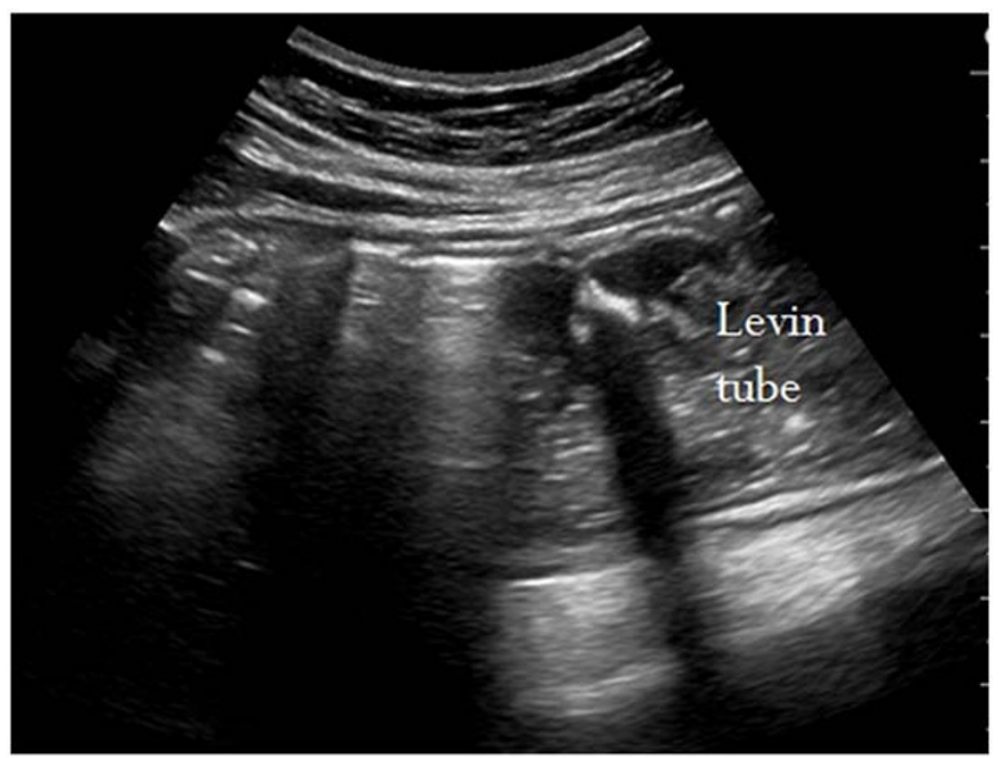

Figure 2 Sonographic visualization of a nasogastric tube. The weighted tip appears as a hyperechogenic line with a posterior acoustic shadow. 


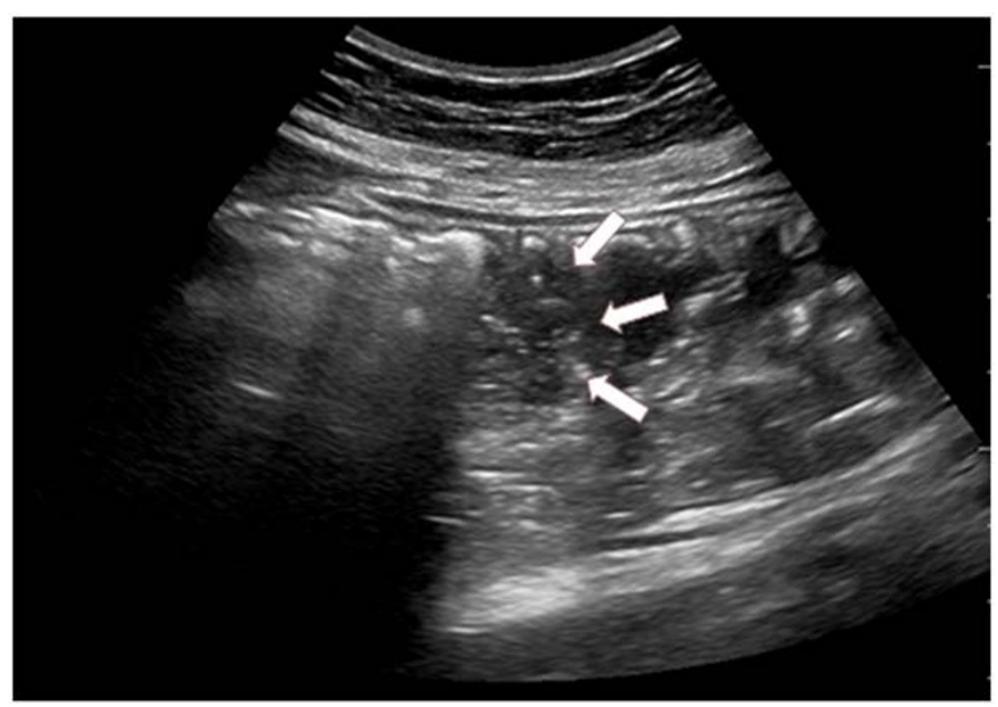

Figure 3 A mixture of $40 \mathrm{ml}$ normal saline with $10 \mathrm{ml}$ air was injected into the tube to visualize the hyperechogenic "fog" existing at the tip of the tube (white arrows).

was greater than 5 , and 2 of these patients had received anti-ulcer medication through a NGT, and 1 patient was alkali poisoned. The gastric contents were not aspirated in $10(21.3 \%)$ patients(6 patients who received endotracheal intubation after bag-valve-mask ventilation, 1 patient with overdose, and 3 patients with gastrointestinal bleeding)(Table 2).

Ultrasound had a lower sensitivity than auscultation (86.4\%) but had a higher specificity (66.7\%) and positive predictive value(97.4\%). Ultrasonography failed to verify gastric placement of the tube in 6 patients (3 patients who had undergone endotracheal intubation, 2 with overdose, and 1 with gastrointestinal bleeding). In another patient, the tube had been placed in the esophagus, but fogging led to a diagnosis of gastric placement.

\section{Table 1 Characteristics of patients}

\begin{tabular}{ll}
\hline Characteristics & $\mathbf{n = 4 7}$ \\
\hline Age (years) & $57.6 \pm 17.2^{*}$ \\
\hline Gender (male/female) & $28(59.6) / 19(40.4)^{\dagger}$ \\
\hline Nasogastric tube indications & \\
\hline Poisoning & $12(25.5)$ \\
\hline Ileus & $2(4.3)$ \\
\hline Intubation & $27(57.4)$ \\
\hline Gastrointestinal bleeding & $6(12.8)$ \\
\hline GCS** & \\
\hline$\leq 8$ & $33(70.2)$ \\
\hline $9-14$ & $14(29.8)$ \\
\hline
\end{tabular}

"Mean \pm SD, SD: standard deviation.

${ }^{\dagger}$ Number (\%).

**Glasgow coma scale.
The kappa value for each test was highest for auscultation at 0.484 compared with chest X-ray examinations, and the kappa value was 0.299 for ultrasonography and 0.444 for $\mathrm{pH}$ analysis(Table 3 ).

Ultrasonography visualized the NGT in the neck area in $39(83 \%)$ patients. In the gastro-esophageal junction, visualization of the nasogastric feeding tube was impaired due to artifacts produced by air in 8 patients (17\%). The tube was directly visualized in the stomach in 6 patients (12.8\%), and fogging occurred in the remaining 33 patients; these results were due to gas interposition(Table 4).

\section{Discussion}

Auscultation could be mistaken for those associated with the correct placement of the NGT because bronchic insertion can lead to gurgling perceived in the epigastric area. Metheny et al. have reported that auscultation has an accuracy of $34.4 \%$ for verifying the placement of a NGT [8]. In an emergency room setting, which is often noisy, an auxiliary method of verifying tube placement is necessary.

In a study by Turgay et al. of 44 patients in intensive care, a nurse inserted the NGT and verified the placement of the tube by auscultation and $\mathrm{pH}$ measurement. Auscultation diagnosed gastric placement in $90.9 \%$ of the patients, whereas radiographic examination showed that the tube was in the stomach in only $88.6 \%$ of patients. However, $\mathrm{pH}$ measurements agreed with radiological examinations in $94.9 \%$ of cases. Thus, Turgay et al. argued that $\mathrm{pH}$ measurement was a more accurate and reliable test than auscultation. It has also been reported that bedside $\mathrm{pH}$ measurements can drastically 
Table 2 Comparison of predictive validity

\begin{tabular}{|c|c|c|c|c|c|c|}
\hline \multirow[t]{2}{*}{ Evaluation method } & \multicolumn{2}{|l|}{ Total $(n=47)$} & \multirow[t]{2}{*}{ Sensitivity (\%) } & \multirow[t]{2}{*}{ Specificity (\%) } & \multirow[t]{2}{*}{ PPV (\%) } & \multirow[t]{2}{*}{ NPV (\% } \\
\hline & $\begin{array}{l}\text { correct } \\
\text { position }(n=44)\end{array}$ & $\begin{array}{l}\text { incorrect } \\
\text { position }(n=3)\end{array}$ & & & & \\
\hline Ultrasound (+) & 38 & 1 & \multirow[b]{2}{*}{86.4} & \multirow[b]{2}{*}{66.7} & \multirow[b]{2}{*}{97.4} & \multirow[b]{2}{*}{25.0} \\
\hline$(-)$ & 6 & 2 & & & & \\
\hline Auscultation (+) & 44 & 2 & \multirow[b]{2}{*}{100.0} & \multirow[b]{2}{*}{33.3} & \multirow[b]{2}{*}{95.7} & \multirow[b]{2}{*}{100.0} \\
\hline$(-)$ & 0 & 1 & & & & \\
\hline $\mathrm{pH}(+)$ & 31 & 1 & \multirow[b]{2}{*}{91.2} & \multirow[b]{2}{*}{66.7} & \multirow[b]{2}{*}{96.9} & \multirow[b]{2}{*}{40} \\
\hline measuring $^{*}(-)$ & 3 & 2 & & & & \\
\hline
\end{tabular}

PPV: positive predictive value.

NPV: negative predictive value.

${ }^{*} \mathrm{pH}$ measuring: The contents were not aspirated in 10 patients.

reduce the necessity of radiological examination [10]. But, we could not determine the tube placement in 10 patients $(21.3 \%)$ because the contents were not aspirated. In emergency room patients with low consciousness, aspiration of the gastric contents (even in patients with a nasogastric tube in place) was frequently impossible due to either bag-valve-mask ventilation during intubation or the presence of large amounts of gastric air in patients with intestinal obstruction or paralytic intestinal adhesion. Also, Some study also reported that the $\mathrm{pH}$ method was inappropriate for distinguishing tube placement within the bronchial tubes or the small intestine in patients with reduced gastric acidity $[13,14]$. In this study, the complete history of the patients' use of medications, such as H2 blockers, was not known. However, $\mathrm{pH}$ analysis provided false negative results in several cases, including in a patient who was taking a stomach medication and was admitted to the emergency room due to gastrointestinal bleeding, in a patient who was routinely administered food and medication through a NGT, and in a patient with alkali poisoning. These findings suggest that verifying NGT placement with the $\mathrm{pH}$ method alone has limitations, and interpretation of these data should be made with careful consideration of the clinical status and medical history of each patient.

Ultrasonography is convenient, fast, noninvasive, and has been widely used as a diagnostic examination

Table 3 Number of correct classification and results of Cohen Kappa analysis

\begin{tabular}{llllr}
\hline $\begin{array}{l}\text { Evaluation } \\
\text { method }\end{array}$ & $\begin{array}{l}\text { Correct } \\
\text { placement }\end{array}$ & $\begin{array}{l}\text { Incorrect } \\
\text { placement }\end{array}$ & K & p \\
\hline Radiology & $44^{*}(93.6)$ & $3(6.4)$ & & \\
\hline Ultrasound & $39(83.0)$ & $8(17.0)$ & 0.299 & 0.018 \\
\hline Auscultation & $46(97.9)$ & $1(2.1)$ & 0.484 & $<0.001$ \\
\hline pH measuring $^{\dagger}$ & $32(86.5)$ & $5(13.5)$ & 0.444 & 0.005 \\
\hline${ }^{*}$ Number $(\%)$ & & & &
\end{tabular}

*Number (\%).

${ }^{\dagger} \mathrm{pH}$ measuring: The contents were not aspirated in 10 patients. technique since its introduction. It has almost no spatial or temporal restrictions, and its effectiveness as a diagnostic tool and procedure has been established worldwide. Vigneau et al. conducted a double-blind experiment in which a fellow who received brief (approximately 2 hours) training successfully inserted the NGT into 33 intensive care unit patients. This study showed that ultrasonography had $97 \%$ sensitivity and could be performed in a shorter time than conventional radiological examinations. The authors also suggested that a basic chest $\mathrm{x}$-ray should be taken in patients in whom tube placement could not be verified using ultrasonography [15]. A study by Chenaitia $\mathrm{H}$. et al. also found that NGT placement could be easily determined by ultrasonography in prehospital managment [14]. This shows that ultrasonography is a possible method for verifying the placement of the NGT.

The present study yielded a lower accuracy for ultrasonography than other studies for several reasons. First, because the patients had a low consciousness level in this study, the examination was performed with the patients in a supine position. In cases of obese or excessively mobile patients, it was difficult to posteriorly observe the NGT in the cervical region. Furthermore, it was often difficult to visualize the esophagogastric junction or the NGT directly because of the large volume of gas in the gastrointestinal tract. However, even without direct visualization, gastric placement of the NGT could be verified by ultrasound in 33 patients $(70.2 \%)$ through

Table 4 The results of ultrasonography

\begin{tabular}{lll}
\hline Site & $\begin{array}{l}\text { Visualization } \\
\text { of tube }\end{array}$ & Fogging \\
\hline Neck & $39^{*}(83.0)$ & \\
Gastric-esophageal & & \\
junction & $8(17.0)$ & $33(70.2)$ \\
Stomach & $6(12.8)$ &
\end{tabular}

"Number (\%). 
the fogging that occurred with the injection of normal saline. In this study, the high positive predictive value of ultrasonography could surely reduced the number of chest X-ray and the visualization of the tube directly by ultrasonography or after water and air insufflations rules out incorrect placement. However obviously still requires someone skilled to interpret the images and training to perform the testing.

One limitation of this study includes the difficulty of directly analyzing the accuracy of the ultrasonography examinations due to the low number of cases of incorrect insertions of the NGT. For more accurate results, it will be necessary to conduct studies on a larger number of patients in the future.

\section{Conclusions}

When inserting the NGT into a patient with low consciousness at an emergency center, placement can be first verified by auscultation. Because $\mathrm{pH}$ analysis of the tube aspirate is not possible in some patients and is subject to false negative results in others, we do not recommend that this method be used for secondary verification of tube placement. Verifying NGT placement with ultrasonography has the potential to reduce complications, save time, and reduce unnecessary radiation exposure. However, for cases in which ultrasound cannot verify placement of the NGT by direct visualization or after water and air insufflation, confirmation with chest $\mathrm{x}$-ray is necessary.

\section{Competing interests}

The authors declare that they have no competing interests.

\section{Authors' contributions}

HMK drafted the manuscript. BHS, WJJ, SMC and KNP reviewed data and revised the manuscript. WJJ and SMC managed the data and reviewed critical revisions to the manuscript. BHS and KNP performed data analysis and revised the manuscript. HMK conceived the research and drafted the manuscript. All authors have read and approved the final manuscript.

\section{Acknowledgements}

The authors report this study did not receive any outside funding or support.

\section{Author details}

'Department of Emergency Medicine, College of Medicine, The Catholic University of Korea, St. Vincent's Hospital, Suwon, South Korea. ${ }^{2}$ Department of Emergency Medicine, College of Medicine, The Catholic University of Korea, St. Mary's Hospital, Uijeongbu, South Korea. ${ }^{3}$ Department of Emergency Medicine, College of Medicine, The Catholic University of Korea, St. Mary's Hospital, Seoul, South Korea.

Received: 2 February 2012 Accepted: 21 May 2012

Published: 12 June 2012

\section{References}

1. Roubenoff R, Ravich W: Pneumothorax due to nasogastric feeding tubes: report of four cases, review of the literature, and recommendations for prevention. Arch Intern Med 1989, 149:184-188.

2. Bankier AA, Wiesmayr MN, Henk C: Radiographic detection of intrabronchial malpositions of nasogastric tubes and subsequent complications in intensive care unit patients. Intensive Care Med 1997, 23:406-410.
3. Maruyama K, Shiojima T, Koizumi T: Sonographic detection of a malpositioned feeding tube causing esophageal perforation in a neonate. J Clin Ultrasound 2003, 31:108-110.

4. Metheny NA, Meert KL, Clouse RE: Complications related to feeding tube placement. Curr Opin Gstroenterol. 2007, 23(2):178-182.

5. Meyer $P$, et al: Colorimetric capnography to ensure correct nasogastric tube position. J Crit Care 2009, 24:231-235.

6. Galbois A, et al: Colorimetric capnography, a new procedure to ensure correct feeding tube placement in the intensive care unit: An evaluation of a local protocol. J Crit Care 2011, 26:411-414.

7. Metheny NA, Titler MG: Assessing placement of feeding tubes. Am J Nurs 2001, 101:36-45.

8. Metheny NA, McSweeney M, Wehrle MA, Wiersema L: Effectiveness of the auscultatory method in predicting feeding tube location. Nurs Res 1990, 39(5):262-267

9. Neumann MJ, Meyer CT, Dutton JL, Smith R: Hold that x-ray: aspirate $\mathrm{pH}$ and auscultation prove enteral tube placement. J Clin Gastroenterol 1995, 20(4):293-295.

10. Turgay AS, Khorshid L: Effectiveness of the auscultatory and $\mathrm{pH}$ methods in predicting feeding tube placement. J Clin Nurs 2010 19(11-12):1553-1559.

11. Metheny NA, Williams $P$, Wiersema $L$, Wehrle MA, Eisenberg P, McSweeney $\mathrm{M}$ : Effectiveness of $\mathrm{pH}$ measurements in predicting feeding tube placement. Nurs Res 1989, 38:280-285.

12. Mertheny NA, Reed L, Wiersema L, McSweeney M, Wehrle MA, Clark J: Effectiveness of $\mathrm{pH}$ measurements in predicting feeding tube placement: an update. Nurs Res 1993, 42:324-331.

13. Harrison AM, Clay B, Grant MJ, Sanders SV, Webster HF, Reading JC, Dean JM, Witte MK: Non-radiographic assessment of enteral feeding tube position. Crit Care Med 1997, 25:2055-2059.

14. Chenaitia H, Brun PM, Querellou E, Leyral J, Bessereau J, Aimé C, Bouaziz R, Georges A, Louis F: WINFOCUS (World Interactive Network Focused On Critical Ultrasound) Group France: Ultrasound to confirm gastric tube placement in prehospital managment. Resuscitation 2012, 83:447-451.

15. Vigneau C, Baudel JL, Guidet B, Offenstadt G, Maury E: Sonography as an alternative to radiography for nasogastric feeding tube location. Intensive Care Med 2005, 31(11):1570-1572.

doi:10.1186/1757-7241-20-38

Cite this article as: Kim et al:: The effectiveness of ultrasonography in verifying the placement of a nasogastric tube in patients with low consciousness at an emergency center. Scandinavian Journal of Trauma Resuscitation and Emergency Medicine 2012 20:38.

\section{Submit your next manuscript to BioMed Central and take full advantage of:}

- Convenient online submission

- Thorough peer review

- No space constraints or color figure charges

- Immediate publication on acceptance

- Inclusion in PubMed, CAS, Scopus and Google Scholar

- Research which is freely available for redistribution 